\section{Sponges out of their depth}

\section{Michelle Kelly-Borges}

SPONGES are impressively adaptable to their environment. But are they biologically plastic to the extent of losing the very characters that define their phylum, the Porifera?

On page 333 of this issue ${ }^{1}$, Vacelet and Boury-Esnault describe a deep-sea sponge that possesses an elaborate and atypical mode of feeding, and has lost the characteristic sponge aquiferous system and feeding cells. The organism is a member of the genus Asbestopluma, family Cladorhizidae. Hook-shaped spicules are, oddly, located on the outside of body filaments, forming an adhesive surface from which small crustaceans can rarely escape (see cover). Once captive, the prey is gradually enveloped in migrating cells, and digestion is complete after several days. This remarkable sponge is effectively a carnivore.

A twist to the story is that Vacelet and Boury-Esnault found their specimens of Asbestopluma in a Mediterranean cave, $18-24 \mathrm{~m}$ below the sea surface. The sponge's nearest relatives are always bathyal, bathyo-abyssal and even hadal, one species reaching depths of $8,840 \mathrm{~m}$ in the Pacific. Presumably cold water trapped within the cave, together with limited nutrient resources and a lack of light, approximates to the conditions of the deepest Mediterranean ${ }^{2}$. The discovery of these sponges in such a shallow and easily accessible habitat will greatly advance studies of their physiology and life history that are impossible to carry out in their normal deep-sea habitat.

Discovery of Asbestopluma within this 'bathyal' cave raises intriguing questions about the origin of this sponge population, as the genus has never previously been found in the Mediterranean. How and when, for instance, did the species arrive in the cave? One possibility is that it originated from a chance colonization event. This new Asbestopluma is very similar to a near relative found in the deep North Sea, suggesting that this might be the source of the potential founder. If so, however, the speciation event must have occurred within the past 7,000 years, since submergence of the cave in the Holocene sea-rise, an improbably short time for the evolution of a new species through isolation. Perhaps a more plausible explanation is that the cave inhabitants arrived on strong upwelling currents, from unknown populations in the deeper, unexplored cliffs, caves and overhangs of the Cassidaigne Canyon, $7 \mathrm{~km}$ distant.

However the sponges arrived in the cave, there is also the question of larval supply and population maintenance. We know that 'normal' deep-sea cladorhizid sponges incubate very large embryos, but larvae have never been seen. Vacelet and Boury-Esnault have found only a few small embryos in specimens examined from the cave population, which is unex-

sponges in the family Cladorhizidae possess hooked filaments, lack an aquiferous system, and are macrophagous. Other filter-feeding invertebrates such as tunicates and bivalves are also macrophagous in deep-sea environments, and up to 30 per cent of the bivalve fauna of deep seas may be macrophagous ${ }^{6}$. It just so happens that a sponge's filter-feeding capacity, conferred by the presence of the diagnostic choanocyte feeding cells, is the very capacity that might be lost in any filter feeder within the deep-sea environment.

As a whole, the sponges form a significant component of worldwide marine benthic communities ${ }^{5}$ and are among the most genetically variable organisms ${ }^{7}$. They are one of the oldest metazoan groups, and as such studies on sponges have contributed a great deal to our understanding of life on Earth. Their complex immune and cellaggregation systems have led us to a greater understanding of the role of the cell surface in cell and tissue recognition. Higher metazoan gene homologues in sponges, including the homeobox $^{8}$, ribosomal $\mathrm{RNA}^{9}$, lectins, ubiquitin and immunoglobulin-like molecules ${ }^{10}$, are being sequenced at an ever-increasing rate. These so-called primitive organisms also possess

pected as spermatogenesis is so frequent. This is very different from another sponge in the cave, the hexactinellid Oopsacas, which produces embryos and larvae yearround $^{2,3}$. It is yet to be seen, then, whether the Asbestopluma population is capable of a complete sexual reproductive cycle under cave conditions.

The sponge has an unusual hydroid-like morphology. Although the filaments of Asbestopluma differ cytologically from the asexual reproductive filaments of other sponge genera, like them they may break or pinch off and re-establish. Asexual reproduction is surprisingly common in a diversity of sponge morphologies, and the recruits generated may have a remarkable behavioural and survivorship capability ${ }^{4}$.

The discovery of macrophagy in Asbestopluma leads Vacelet and Boury-Esnault to question the validity of the diagnostic characters that define lower invertebrate phyla. There is the idea that, if Asbestopluma were not so clearly related to other Porifera, their unique body plan would qualify them as a distinct phylum. Indeed, there are those who consider that the syncytial organization of glass sponges challenges the retention of the Class Hexactinellida within the Porifera ${ }^{5}$.

There is, however, evidence that most the widest diversity of biologically active compounds of any marine phylum.

Apart from its intrinsic interest to those who study the Porifera, then, the paper by Vacelet and Boury-Esnault reaffirms a basic message for biologists in general - it seems that whenever sponges need to do something, they are able to do it.

Michelle Kelly-Borges is in the Department of Zoology, The Natural History Museum, London SW7 5BD, UK.

1. Vacelet, J. \& Boury-Esnault, N. Nature 373, 333-335 (1995).

2. Vacelet J Boury-Esnault N. \& Harmelin J-G. Deep-sea Res. 41, 965-973(1994).

3. Boury-Esnault, N. \& Vacelet, J. in Sponges in Time and Space: Biology, Chemistry, Paleontology (eds Van Soest, R., Van Kempen, Th. M. G. \& Braekman, J. C.) 407-415 (Balkema, Rotterdam, 1994).

4. Battershill, C. N. \& Bergquist, P. R. in New Perspectives in Sponge Biology (eds Rützler, K., Macintyre, V. V. \& Smith, K. P.) 397-403 (Smithsonian institution Press. Smith, K. P.) 397-403 (

5. Bergquist, P. R. in The Origins and Relationships of Lower Invertebrates (eds Morris, S. C., George, J. D., Gibson, R. \& Platt, H. M.) 14-27 (Clarendon, Oxford, 1985).

6. Knudsen, J. in Pathways in Malacology (eds Spoel, S. V. D., Bruggen, A. C. V. \& Lever, J.) 195-224 (Bohn, Sheltema and Holkema, Utrecht, 1979)

7. Sole-Cava, A M. \& Thorpe, J.P. in Sponges in Timeand Space: Biology, Chemistry. Paleontology (eds Van Soest, R., Van Kempen, Th. M. G. \& (Braekman, J. C.) 55-64 R., Van Kempen, Th. M. G. \&
(Balkema, Rotterdam, 1994)

8. Seimiya, M., Watanabe, Y. \& Kurosawa, Y. Zool. Sci. 9 , $1213(1992)$

9. Kelly-Borges, M. \& Pomponi, S. A. Molec. mar. Biol. Biotech. 3, 87-103(1994)

10. Müller, W. E. G. et al. Naturwissenschaften (in the press). 